\title{
Experimental Investigation into the Bedding Plane Slip Effect on the Overlying Strata Behavior in Longwall Top Coal Caving of Soft Coal Seam
}

\author{
Hengfeng Liu $\mathbb{D}^{1,2}$, Jixiong Zhang $\mathbb{D}^{1,2}$ Nan Zhou $\mathbb{D}^{1,2}$,2 Qiang Sun, ${ }^{1,2}$ Meng Li, \\ and Zhizhong $\mathrm{Cui}^{1,2}$ \\ ${ }^{1}$ State Key Laboratory of Coal Resources and Safe Mining, China University of Mining \& Technology, Xuzhou 221116, China \\ ${ }^{2}$ School of Mines, China University of Mining \& Technology, Xuzhou 221116, China \\ Correspondence should be addressed to Jixiong Zhang; cumtzjxiong@163.com
}

Received 6 April 2019; Accepted 9 July 2019; Published 5 August 2019

Academic Editor: Khalid Abdel-Rahman

Copyright (c) 2019 Hengfeng Liu et al. This is an open access article distributed under the Creative Commons Attribution License, which permits unrestricted use, distribution, and reproduction in any medium, provided the original work is properly cited.

\begin{abstract}
Bedding plane shear slip becomes more obvious in rock strata with quite different mechanical properties. A composite beam model considering the behaviors of the main roof and the immediate roof in the "three-soft" coal seam is established based on physical similarity simulation experiments and the slip theory in this paper. The movement and failure of the overlying strata and the mechanism of the bedding plane slip at the 2211 working face are studied by experimental and theoretical analysis. The results suggest that the front abutment stress distribution occurs $50 \mathrm{~m}$ ahead of the working face, the initial caving interval of the main roof is $55 \mathrm{~m}$, and the peak stress appears at a distance 20 to $32 \mathrm{~m}$ ahead of the working face. The bedding plane slip areas can be divided into the obvious slip area and the slight slip area along the mining direction. The range of the obvious slip area becomes wider and the range of the slight slip area grows to be narrower as the working face advances. The bedding plane slip becomes steady after gradual increase and leads to the subsidence of the overlying strata in the "three-soft" coal seam. The observed initial caving interval of the main roof by field measurement is $51 \mathrm{~m}$, which is consistent with the results of physical similarity simulation experiments and theoretical analysis. The results demonstrate that the beam slip model proposed in this paper is reasonable and able to describe the behaviors of overlying strata and bedding plane slip.
\end{abstract}

\section{Introduction}

Complex problems related to soft rocks are often encountered in engineering projects. As a worldwide issue from the 1960 s, the soft rock problem has great influence on coal mine construction and mining safety [1], such as resulting in great mining difficulty, high technical cost, and low production efficiency. At present, it is of great significance for sustainable development, and there are many "three-soft" coal seams in China. The "three-soft" coal seam (TSCS) in this paper refers to a coal seam with soft roof, soft coal, and soft floor in coal mining [2]. The roof of TSCS is extremely fragile, and the coal walls often break during the mining process; that is, roof fall, rib spalling, and constraint of support structures occur from time to time. This not only affects the mining safety and efficiency, but threatens the life safety of mine workers. Thus, it is necessary to study the overburden movement and failure during the TSCS mining. A significant amount of research has been carried out on soft rocks, top coal caving, and TSCS mining.

Tsesarsky et al. [3] addressed the stability analysis in two different scales (local-discontinuous and global-continuous) by developing a realistic approach for a three-dimensional finite element analysis on the shallow underground openings excavated in soft and discontinuous rock masses. Yadav et al. [4] studied on the deformation evolution of model soft rocks during orthogonal cutting through high-resolution imaging of orthogonal cutting experiments under 2D plane-strain conditions. Bizjak and Petkovšek [5] suggested that the settlement of vault is most prominent after the excavation of 
a soft rock tunnel and timely construction of a reverse arch and closed lining can effectively reduce the displacement of the tunnel. Corthésy et al. [6] developed a modified doorstopper technique and affirmed its advantages in soft rock engineering. Shin et al. [7] proposed a preliminary guideline for evaluating the protection zone of the blast vibration and utilized a numerical method for dynamic modeling of a tunnel in soft rocks. Yang et al. [8] analyzed the mechanism of large deformation and control technology of deep soft rock roadways and put forward an improved bolt-cable-reticulated shell supporting mode. Kikumoto et al. [9] established a constitutive model for soft rocks incorporating structural healing and decay in the context of the extended critical state theory. Singh et al. [10] pointed out that large deformation occurs on the premise of weak surrounding rocks under high in situ stress. Qin et al. [11] considered that the support for deep soft rock roadways under dynamic pressure is a major technical challenge, and a support technique was proposed based on the control effect of different support methods. He et al. $[11,12]$ proposed the technique of constant resistance and large deformation bolt support based on nonlinear large deformation theory of soft rocks. Wang and Pang [13] studied the adaptability evaluation and technical principle of fully mechanized top coal caving mining in extrathick coal seams. Vakili and Hebblewhite [14] introduced a new conceptual model for investigating top coal caving mechanism through analytical, observational and empirical methods. Unver and Yasitli [15] studied the top coal caving mechanism at the M3 longwall panel of Omerler Underground Mine using a finite difference code. Gao et al. [16] put forward an innovative numerical approach to simulate progressive caving of strata above a longwall face. $\mathrm{Wu}$ et al. [17] investigated the mechanism of coal wall spall and disaster-causing mechanism in fully mechanized top coal caving face with a large dip angle. Wang et al. [18] studied the support technology of key parts of roadways with large dip angle in the soft coal seam. Xu et al. [19] performed an experimental research on the overburden movement and fissure evolution of fully mechanized caving face. Yao et al. [20] studied the applicability of large mining height-combined sliding support in "three-soft" coal seams. These research studies promote the technique and theory development of TSCS mining. However, the strata movement law of TSCS mining still needs to be further studied [21] and many scholars ignore the influence of bedding plane slip on the overburden movement, especially in the case of huge differences between rock strata. In the process of mining-induced bending deformation, the shear slip among rock layers is more obvious due to incompatible deformation. Therefore, the slip effect is introduced in this work to study the overburden movement failure and bedding plane slip mechanism in the "three-soft" coal seams.

Based on the geological conditions at Linnancang Mine and laboratory tests, physical similarity simulation experiments are carried out and the overburden movement and bedding plane slip mechanism of fully mechanized top coal caving face in the TSCS are analyzed through mechanical analysis and similarity simulation experiments. The research results are expected to provide some reference for the safe mining of TSCSs.

\section{Engineering Background}

The $11 \#$ coal seam studied in this paper is in the No. 2 mining district at Linnancang Mine, China, which has a small change of dip angle and thickness variation. The roof and floor are mainly partially carbonaceous Claystone which are soft and fragile, and the coal body is soft as well. The immediate roof is composed of dark gray Claystone with a thickness of $2.1 \mathrm{~m}$ and the immediate floor consists of light gray Claystone with a thickness of $2.5 \mathrm{~m}$. The 2211 working face is located northeast of the coal seam. The elevation of the ground is $+5.30 \mathrm{~m}$ to $+5.97 \mathrm{~m}$, the elevation of the working face is -490.7 to $-515.5 \mathrm{~m}$, the strike length is $456.3 \mathrm{~m}$, the slope length is $59.5 \mathrm{~m}$, and the dip angle is $13^{\circ}$. Having a bulk density of $1.43 \mathrm{t} / \mathrm{m}^{3}$, coal seam has an average thickness of $4.2 \mathrm{~m}$ and is mainly powdery durian that is soft and easy to fall. The detailed layout is shown in Figure 1.

There are many explanations about the concept of soft rocks, which can be divided into descriptive definition, indexing definition, and engineering definition. Among them, the International Society of Rock Mechanics (ISRM) offers an indexing definition: the soft rock is defined as the rock having uniaxial compressive strength between $0.25 \mathrm{MPa}$ and $25 \mathrm{MPa}$ [22]. Figure 2 shows the characteristics of the "three-soft" coal seam. The pressure behaviors at the working face of the "three-soft" coal seam include severe roof damage, serious rib spalling and roof collapse (gangue inflow), nonobvious first and periodic weighting, uneven supporting force, and low working resistance. The pressure features of the coal walls contain large pressure exerted on the support structures, huge deformation, obvious front abutment stress, which can cause severe rib spalling and floor heave. Hence, the mining pressure behaviors in the fully mechanized top coal caving face of the "three-soft" coal seam can be summarized as follows: (1) the first and periodic weighting is not obvious; (2) the resultant pressure point of the top coal moves forward, causing unreasonable performance of the rear support; (3) the deformed roof is easy to fall and inflow gangue; damage of the coal walls may lead to serious rib spalling; and low strength of the floor can easily induce floor heave. These features make the problem of roof fall more serious and result in more support work, which greatly increases mining and supporting difficulty, leading to heavy economic losses and casualties. Therefore, deformation and bedding plane slip mechanism are studied in this paper based on experimental and theoretical analysis.

\section{Model Construction}

3.1. Test Procedure. Before conducting the physical similarity simulation experiment, the geomechanical properties of coal and rocks are obtained based on sampling and laboratory tests. Then, the components of the simulation materials and the similarity ratio are determined according to the test results. The specific research process is illustrated as below (Figure 3). 


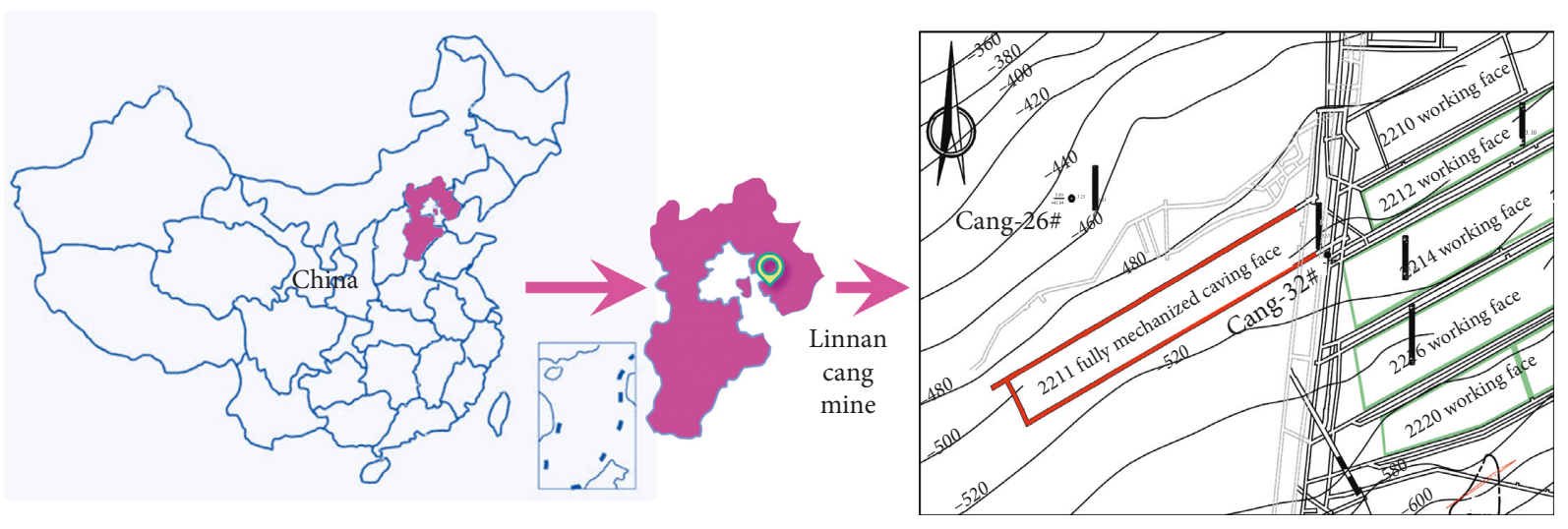

FIGURE 1: Layout of 2211 fully mechanized top coal caving face.
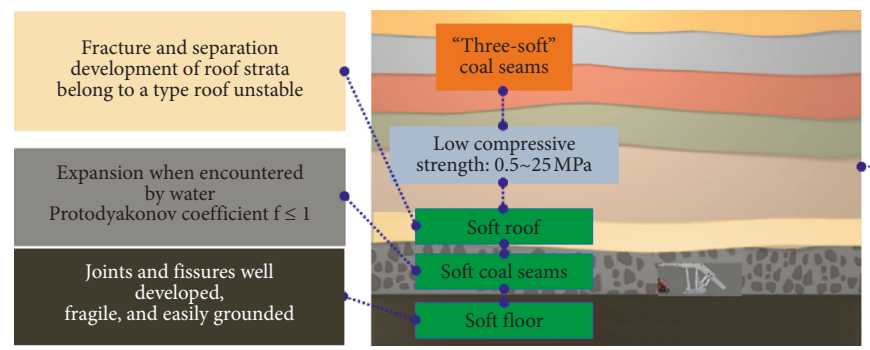

\begin{tabular}{|c|c|c|c|}
\hline Histogram & Type & Thickness & Lithology description \\
\hline & $9 \#$ coal & $2.4 \mathrm{~m}$ & $\begin{array}{c}\text { Durain, semi-clarian to durain, } \\
\text { piece-shape, or flake-shake }\end{array}$ \\
\cline { 2 - 4 } & Fine sandstone & $10.6 \mathrm{~m}$ & $\begin{array}{c}\text { The composition in mainly quartz, } \\
\text { and the lithology is relatively soft }\end{array}$ \\
\cline { 2 - 4 } & Claystone & $2.1 \mathrm{~m}$ & Soft and fragile \\
\hline $9 \#$ coal & $4.2 \mathrm{~m}$ & $\begin{array}{c}\text { Durain is predominent, powdered, } \\
\text { loose, and easy to fall }\end{array}$ \\
\hline Clay rock & $2.5 \mathrm{~m}$ & $\begin{array}{c}\text { Mud cement with a small } \\
\text { amount of plant debris fossils }\end{array}$ \\
\hline & Coarse sandstone & $20.7 \mathrm{~m}$ & $\begin{array}{c}\text { With siltstone strips, partially large dip } \\
\text { angle and dislocated }\end{array}$ \\
\hline
\end{tabular}

FIgURE 2: Characteristics of the "three-soft" coal seam.

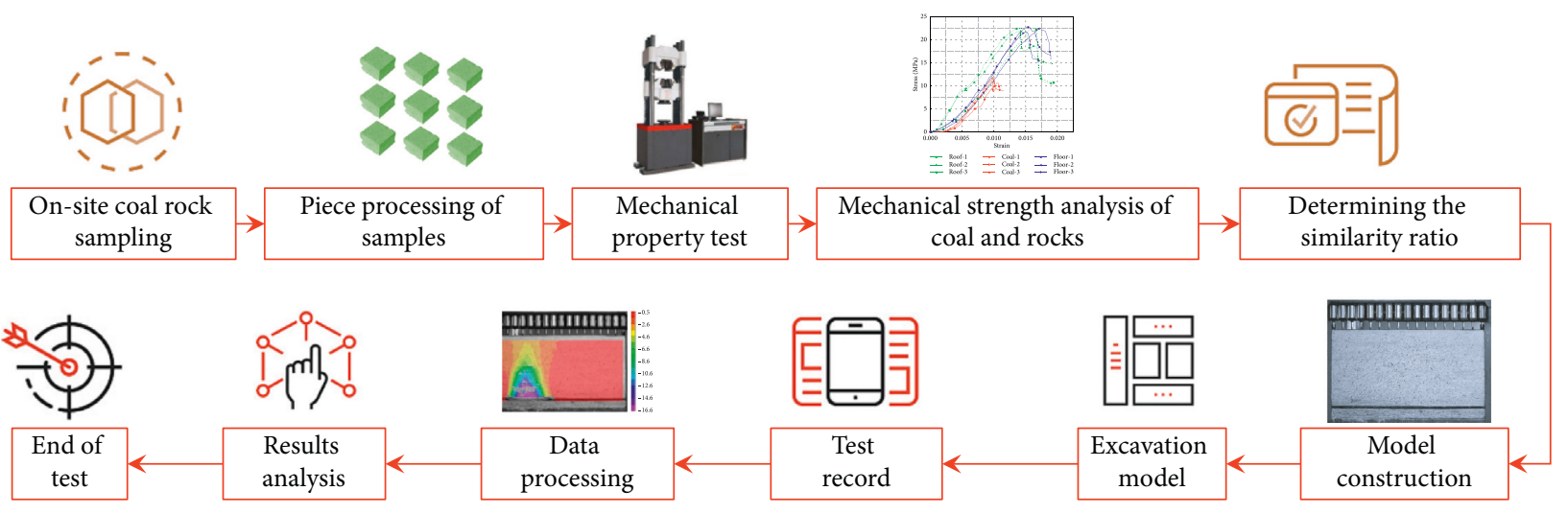

Figure 3: Experiment and research process.

3.2. Mechanical Property Test. The rock and coal samples collected from the mining area at Linnancang Mine were processed to numbered specimens. Physical and mechanical tests were carried out on these specimens. The test design and equipment are shown in Figure 4 [23] and Table 1.

3.3. Test Model Construction. In order to observe the evolution characteristics of overburden fissures and horizontal slip of bedding planes in the working face, the parameters of coal and rocks for the similarity experiment were determined based on the geological conditions of the 2211 working face and the mechanical property test results (Table 2 ).

A simulation model of $2.5 \mathrm{~m} \times 2 \mathrm{~m} \times 1.5 \mathrm{~m}$ was established based on the theory of similarity (Figure 5). The geometry similarity ratio is $1: 150$, and the height is $225 \mathrm{~m}$.
The model mining height was determined as $3.7 \mathrm{~m}$ based on field measurement and calculation. 6 sets of pressure boxes with an interval of $30 \mathrm{~cm}$ are used to monitor the stress change of the main roof during the mining process. The noncontact field strain measurement system (Vic-2D system) was applied [24-26] to monitor the damage process of the roof and overlying strata, the fissure development, and the horizontal slip of bedding planes.

\section{Test Results and Analysis}

4.1. Mechanical Property Test Results. Through the physical and mechanical tests on the three kinds of specimens, the corresponding compressive, tensile and shear stress-strain curves are obtained (Figures 6-8). 

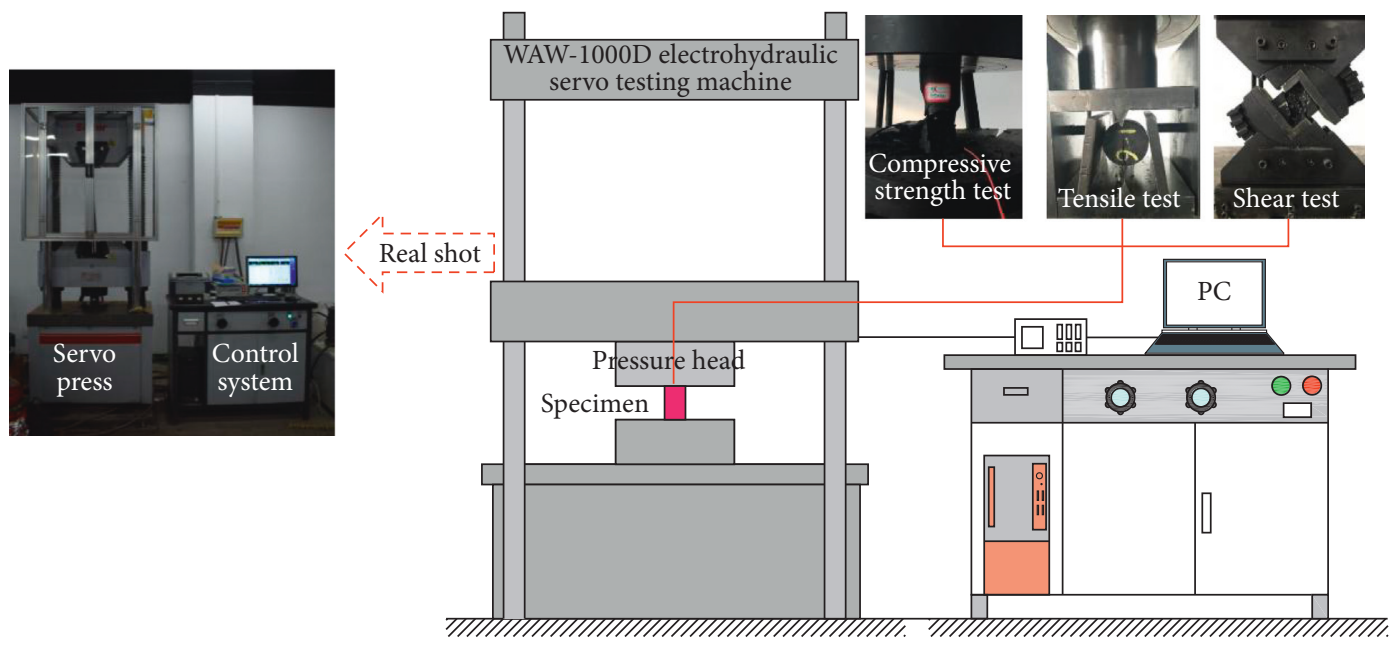

Figure 4: Test design and equipment.

TABLE 1: Design of the mechanical property test.

\begin{tabular}{|c|c|c|c|}
\hline Type & Test subject & Quantity & Description \\
\hline Compressive strength test & Roof and floor rocks and coal blocks & 3/group & $\begin{array}{l}\text { The displacement control mode is used by axial } \\
\text { loading, the loading rate is } 0.2 \mathrm{~mm} / \mathrm{s} \text {, the stress and } \\
\text { strain parameters are fully acquired, and the } \\
\text { frequency of acquisition is } 0.5 \mathrm{~s} \text {. }\end{array}$ \\
\hline Tensile test & Roof and floor rocks and coal blocks & 3/group & $\begin{array}{l}\text { Using the Brazilian splitting method, a cylindrical } \\
\text { specimen ( } \varphi 50 \mathrm{~mm}, h=25 \mathrm{~mm}) \text { is applied with } \\
\text { concentrated loading along the diameter of the } \\
\text { specimen, and the specimen breaks in the diameter } \\
\text { direction after being subjected to force. }\end{array}$ \\
\hline Shear test & Roof and floor rocks and coal blocks & 3/group & $\begin{array}{l}\text { The shear angles are selected as } 20^{\circ}, 30^{\circ}, 40^{\circ} \text {, and } 50^{\circ} \text {, } \\
\text { each shear angle has a corresponding set of } \sigma \text { and } \tau \\
\text { values during the test, and linear fitting is performed } \\
\text { according to the } \sigma \text { and } \tau \text { values. }\end{array}$ \\
\hline
\end{tabular}

As shown in Figures 6 and 7, the uniaxial compressive strengths of the three kinds of specimens, i.e., roof rocks, coal blocks, and floor rocks, are $22.39 \mathrm{MPa}, 11.20 \mathrm{MPa}$, 22.35 $\mathrm{MPa}$, respectively, and their tensile strengths are 2.03 $\mathrm{MPa}, 0.45 \mathrm{MPa}$, and $1.30 \mathrm{MPa}$, respectively. The normal stresses of the three specimens are positively correlated with their shear stresses (Figure 8). The cohesion (C) of the coal specimens and the rock specimens and their internal friction angles $(\varphi)$ can be obtained based on the slopes and intercepts of the fitting curves. The test results show that the cohesion of the roof rock is $1.51 \mathrm{MPa}$, and the internal friction angle is $28^{\circ}$; the floor rock has cohesion of $0.65 \mathrm{MPa}$ and an internal friction angle of $41^{\circ}$; the coal has cohesion of $0.34 \mathrm{MPa}$ and its internal friction angle is $28^{\circ}$. The International Society of Rock Mechanics considers the rocks with the uniaxial compressive strength between $0.5 \mathrm{MPa}$ and $25 \mathrm{MPa}$ as soft rocks. Hence, it can be concluded that the coal, roof, and floor rocks studied in this work have relatively low strength and belong to a typical "three-soft" coal seam (Table 3 ).

4.2. Failure Mechanism of Overburden Movement. Mining operations can cause bending subsidence and fracture of overlying strata, and the fissure development is characterized into two kinds, namely, separation fissures and vertical fissures. With the advancing of the working face, the fissures will experience the development of initiation, propagation, and closure.

As shown in Figure 9, the overburden begins to undergo bending subsidence with the advancement of the 2211 working face. When the working face is advanced to $12.5 \mathrm{~m}$, the first fracture occurs in the immediate roof, and the separation between the main roof and the upper rock layers appears. When the working face advances to $55 \mathrm{~m}$, the initial fracture occurs in the main roof. Hence, it is considered that the initial caving interval of the main roof is $55 \mathrm{~m}$. In addition to the main roof fractured, the overlying strata begin to subside, the separation grows larger, and the fissures continue to develop upward. The main roof breaks many times when the working face advances to $117 \mathrm{~m}$, and there are many separations in the overburden. The vertical fissures penetrate upward and connect with each other and the phenomenon of bending subsidence becomes more apparent. As the working face advances to $210 \mathrm{~m}$, bending subsidence develops to the upper part of the model, the separations gradually close, and the vertical fissures continue to propagate upward. When the process advances to $242 \mathrm{~m}$, the upper surface of the model is severely damaged and the 
TABLE 2: Coal and rock parameters for physical similarity simulation experiment.

\begin{tabular}{|c|c|c|c|c|c|c|c|c|c|}
\hline \multirow{2}{*}{ No. } & \multirow{2}{*}{ Rock stratum } & \multirow{2}{*}{$\begin{array}{l}\text { Thickness } \\
(\mathrm{m})\end{array}$} & \multirow{2}{*}{$\begin{array}{l}\text { Model thickness } \\
(\mathrm{cm})\end{array}$} & \multirow{2}{*}{$\begin{array}{c}\text { Compressive strength } \\
(\mathrm{MPa})\end{array}$} & \multirow{2}{*}{$\begin{array}{c}\text { Simulated intensity } \\
(\mathrm{KPa})\end{array}$} & \multicolumn{4}{|c|}{ Similar materials $(\mathrm{kg})$} \\
\hline & & & & & & $m_{1}$ & $m_{2}$ & $m_{3}$ & $m_{4}$ \\
\hline 1 & Siltstone & 28.8 & 19.2 & 37 & 147.97 & 115.2 & 14.4 & 14.4 & 20.57 \\
\hline 2 & $\begin{array}{l}\text { Medium-grained } \\
\text { sandstone }\end{array}$ & 11.7 & 7.8 & 54 & 215.96 & 46.8 & 3.51 & 8.19 & 8.36 \\
\hline 3 & Siltstone & 26.3 & 17.5 & 34 & 135.97 & 104.9 & 13.13 & 13.13 & 18.75 \\
\hline 4 & Coarse-grained sandstone & 16.6 & 11.1 & 58 & 231.95 & 66.6 & 5 & 11.66 & 11.89 \\
\hline 5 & Siltstone & 16.8 & 11.2 & 32 & 127.97 & 63 & 14.7 & 6.3 & 12 \\
\hline 6 & $\begin{array}{l}\text { Medium-grained } \\
\text { sandstone }\end{array}$ & 14.1 & 9.4 & 52 & 207.96 & 52.88 & 8.81 & 8.81 & 10.07 \\
\hline 7 & Siltstone & 24.9 & 16.5 & 35 & 139.97 & 98.99 & 12.38 & 12.38 & 17.68 \\
\hline 8 & Fine sandstone & 13.6 & 9.1 & 32 & 127.97 & 54.59 & 6.83 & 6.83 & 9.75 \\
\hline 9 & 8\# coal seam & 3.8 & 2.5 & 7 & 28 & 16.41 & 1.64 & 0.7 & 2.68 \\
\hline 10 & Siltstone & 12.6 & 8.4 & 32 & 127.97 & 47.24 & 11.03 & 4.73 & 9 \\
\hline 11 & $\begin{array}{l}\text { Fine } \sim \text { medium-grained } \\
\text { sandstone }\end{array}$ & 7.6 & 5.1 & 42 & 167.97 & 28.69 & 4.78 & 4.78 & 5.46 \\
\hline 12 & Siltstone & 5.7 & 3.8 & 30 & 119.98 & 21.37 & 4.99 & 2.14 & 4.07 \\
\hline 13 & 9\# coal seam & 2.4 & 1.6 & 7 & 28 & 10.5 & 1.05 & 0.45 & 1.71 \\
\hline 14 & Fine sandstone & 10.6 & 7.1 & 25 & 99.98 & 42.59 & 7.46 & 3.2 & 7.61 \\
\hline 15 & Dark gray claystone & 2.1 & 1.4 & 23 & 91.98 & 8.4 & 1.47 & 0.63 & 1.5 \\
\hline 16 & 11\# coal seam & 4.2 & 2.8 & 11.2 & 44.8 & 18.38 & 1.83 & 0.79 & 3 \\
\hline 17 & Dark gray claystone & 2.5 & 1.7 & 20 & 79.98 & 10.19 & 1.79 & 0.77 & 1.82 \\
\hline 18 & Coarse-grained sandstone & 20.7 & 13.8 & 60 & 239.95 & 82.81 & 6.21 & 14.48 & 14.76 \\
\hline
\end{tabular}

Note. $m_{1}$, weight of sand; $m_{2}$, weight of calcium carbonate; $m_{3}$, weight of gyp; $m_{4}$, weight of water.

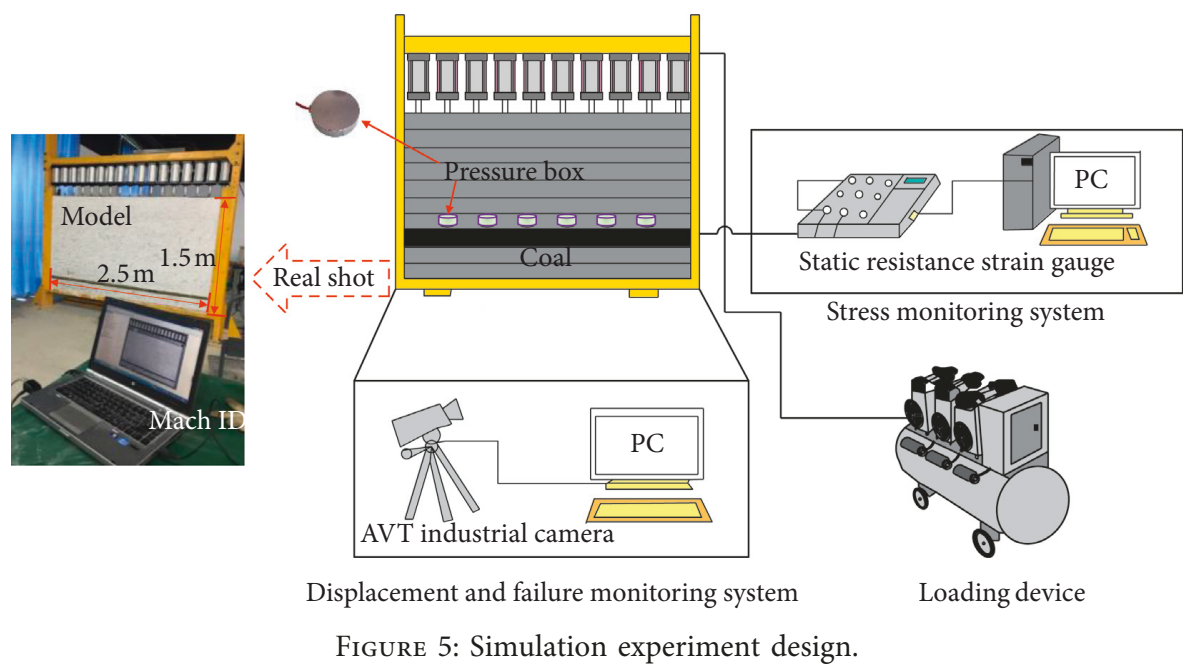

maximum fissure height develops up to $123 \mathrm{~m}$. The overburden subsides completely, the separations reclose, and the vertical fissures have a full development when the working face is advanced to $315 \mathrm{~m}$ (to the mining stoppage line).

From Figures 10 and 11(a), it can be noted that the main roof begins to subside, and the subsidence amount increases gradually, and the subsidence peak value moves forward with the advancing of the working face. When the working face advances to $107 \mathrm{~m}$, the maximum subsidence value of the main roof is $3.0 \mathrm{~m}$. As the working face advances to $242 \mathrm{~m}$, a large area of collapse occurs, and the maximum subsidence value is $3.37 \mathrm{~m}$. When the working face is advanced to the stoppage line $(315 \mathrm{~m})$, the main roof having a maximum subsidence value of $3.5 \mathrm{~m}$ is no longer in a stable state with the passage of time.

The overburden subsidence is accompanied by the redistribution of stress. The distribution and evolution characteristics of the front abutment stress are obtained based on four groups of effective data on the vertical stress of the main roof collected in the similarity experiment, presented in Figure 11(b). As the working face gradually approaches the pressure boxes, the stress (in situ rock stress) at each measuring point shows the trend of being stable first, then increasing, and finally decreasing. In the range of $20 \mathrm{~m}$ to $32 \mathrm{~m}$ ahead of the working face, the stress reaches a peak value; then it slowly drops to $0 \mathrm{MPa}$, and the influence range 


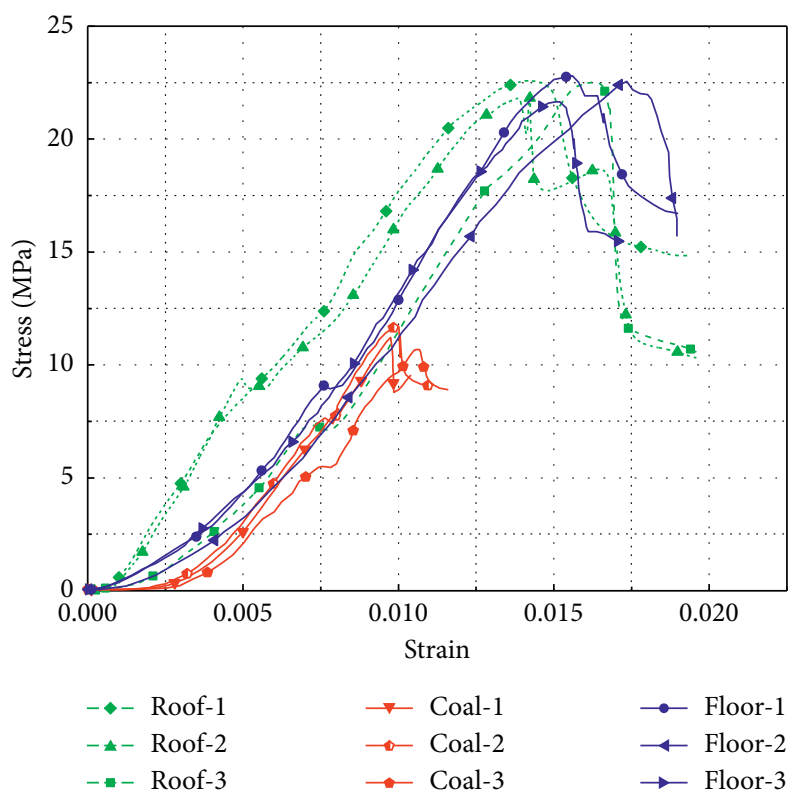

Figure 6: Uniaxial compressive stress-strain curves of coal and rocks.

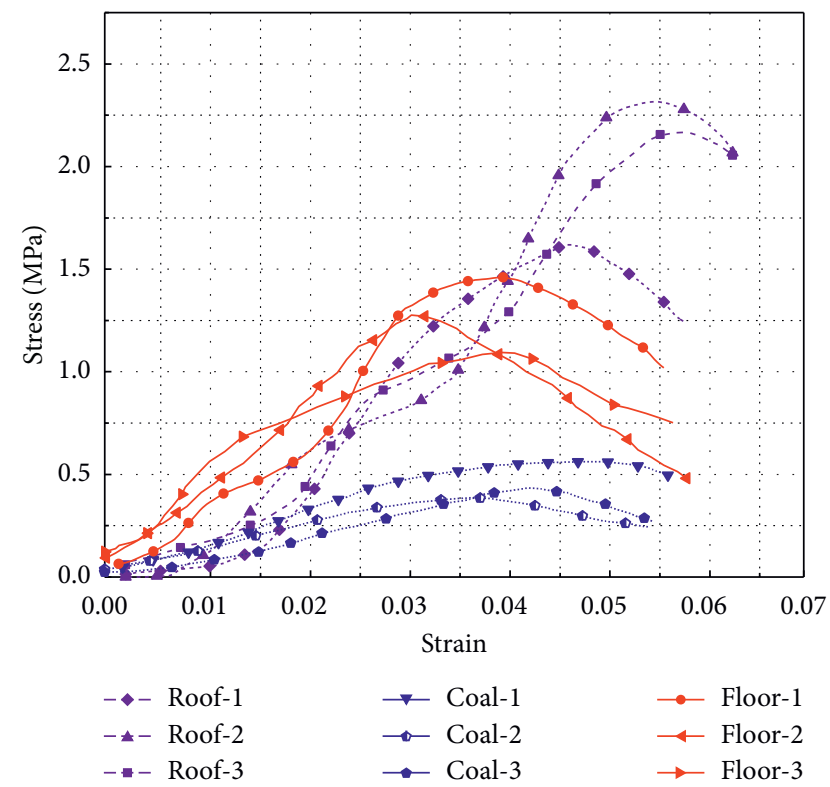

Figure 7: Uniaxial tensile stress-strain curves of coal and rocks.

of the front abutment stress is about $50 \mathrm{~m}$. The front abutment stress of the measuring point 4 reaches a maximum value of $26.6 \mathrm{MPa}$, and its average stress concentration factor is 1.52 . These indicate that the influence range of the front abutment stress of the 2211 working face is large and the position of the peak stress ahead the working face moves forward accordingly.

4.3. Analysis of Bedding Plane Slip Mechanism. According to the contour plots of the horizontal slip of bedding planes with different advance distances (Figure 12), bedding plane slip along the mining direction has obvious zoning area,

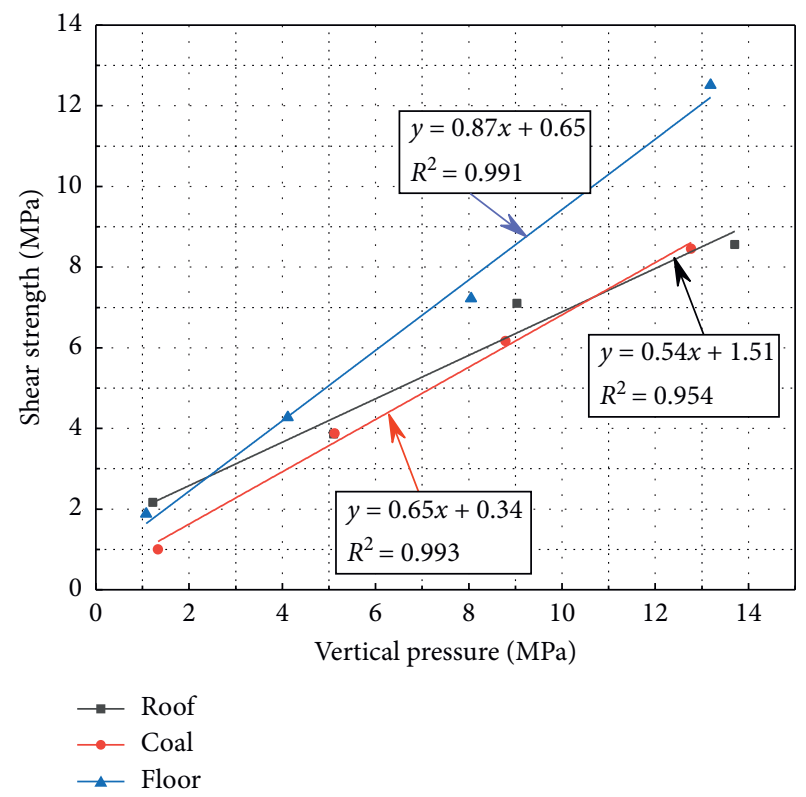

FIgURE 8: Shear test fitting curves of coal and rocks.

which can be divided into the obvious slip area and the slight slip area. The obvious slip area corresponds to the deformation and failure area of overlying strata above the goaf. The obvious slip area shows a positive-negative layer-line distribution in the vertical direction. Each slip layer line presents a positive and negative symmetry distribution with respect to the midpoint of the goaf along the horizontal direction. The slip mainly occurs in the indirect contact position of the rock layers with obvious horizontal fissures. The other area belongs to the slight slip area.

With the advancing of the working face, the obvious slip area increases gradually along the horizontal and 
TABle 3: Physical and mechanical properties of rock and coal samples.

\begin{tabular}{lccccc}
\hline Type & $\begin{array}{c}\text { Uniaxial compressive strength } \sigma_{\mathrm{c}} \\
(\mathrm{MPa})\end{array}$ & $\begin{array}{c}\text { Uniaxial tensile strength } \sigma_{\mathrm{t}} \\
(\mathrm{MPa})\end{array}$ & $\begin{array}{c}\text { Elastic modulus } E \\
(\mathrm{GPa})\end{array}$ & $\begin{array}{c}\text { Cohesion } C \\
(\mathrm{MPa})\end{array}$ & $\begin{array}{c}\text { Internal friction angle } \\
f\left({ }^{\circ}\right)\end{array}$ \\
\hline Roof & 22.39 & 2.03 & 1.60 & 1.51 & 28 \\
11\# coal & 11.20 & 0.45 & 1.24 & 0.34 & 33 \\
seam & 22.35 & 1.30 & 1.49 & 0.65 & 41 \\
Floor & & & & \\
\hline
\end{tabular}

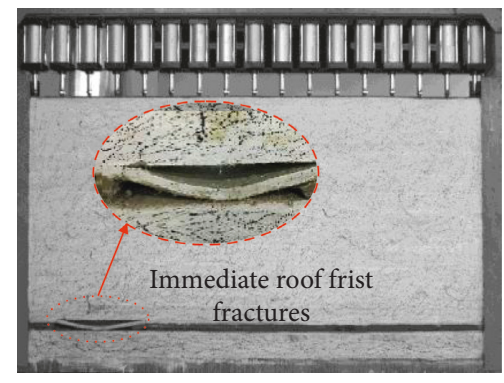

(a)

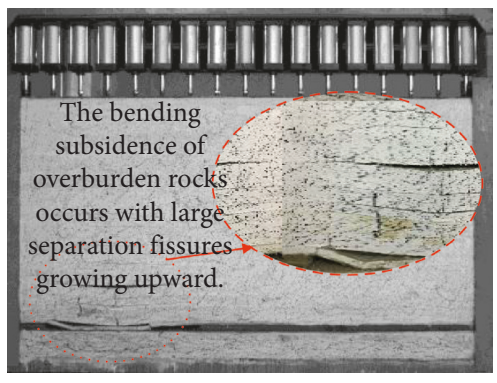

(b)

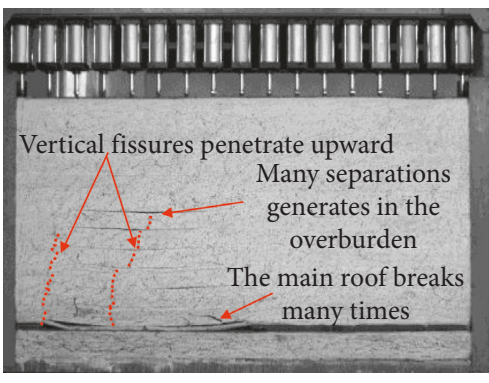

(c)

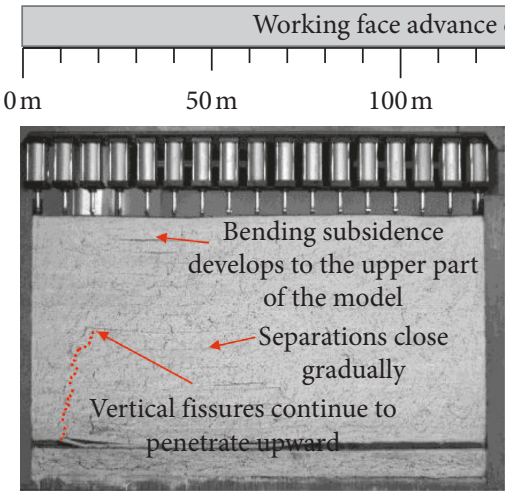

(d)

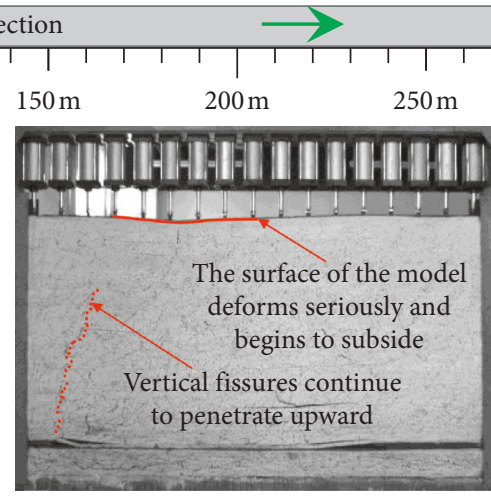

(e)

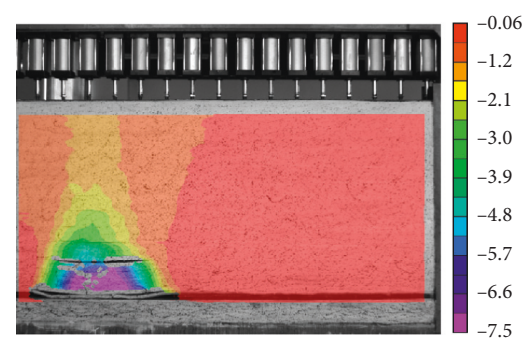

(b)

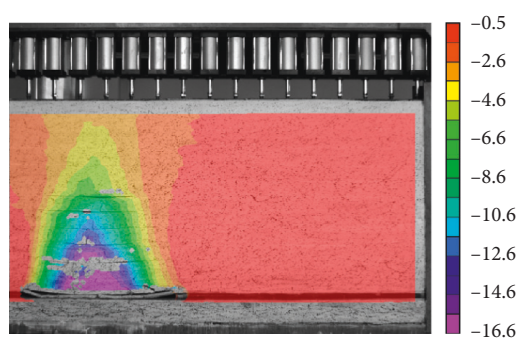

(c)

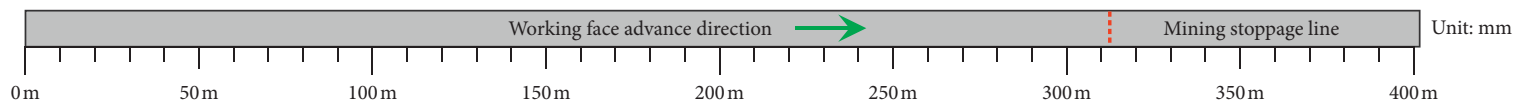

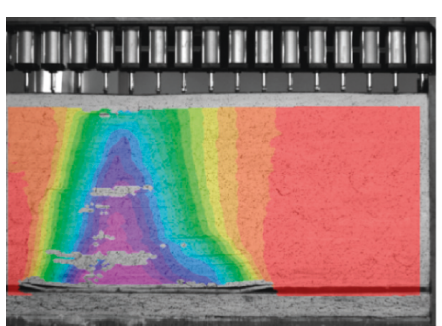

(d)

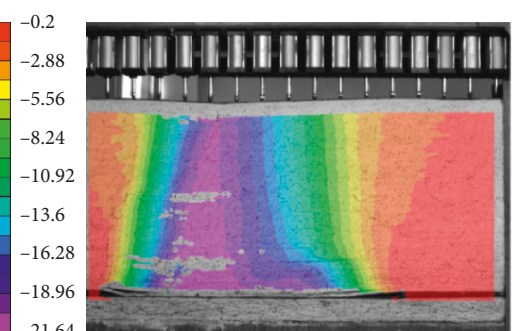

(e)

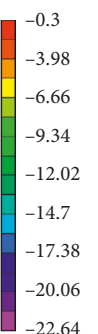

20.06

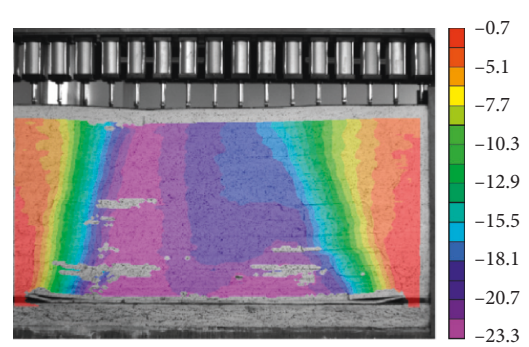

(f)

Figure 10: Contour plots for the characteristics of overburden movement: (a) $12.5 \mathrm{~m}$, (b) $55 \mathrm{~m}$, (c) $117 \mathrm{~m}$, (d) $210 \mathrm{~m}$, (e) $242 \mathrm{~m}$, and (f) $315 \mathrm{~m}$. 


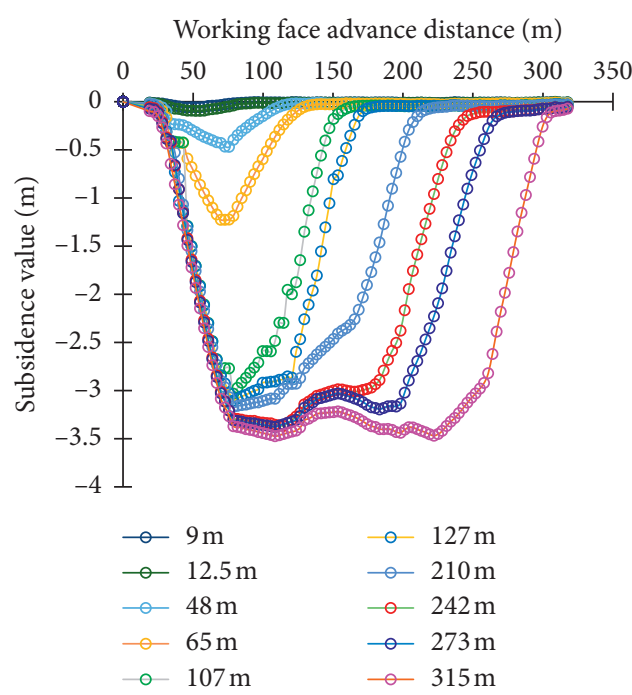

(a)

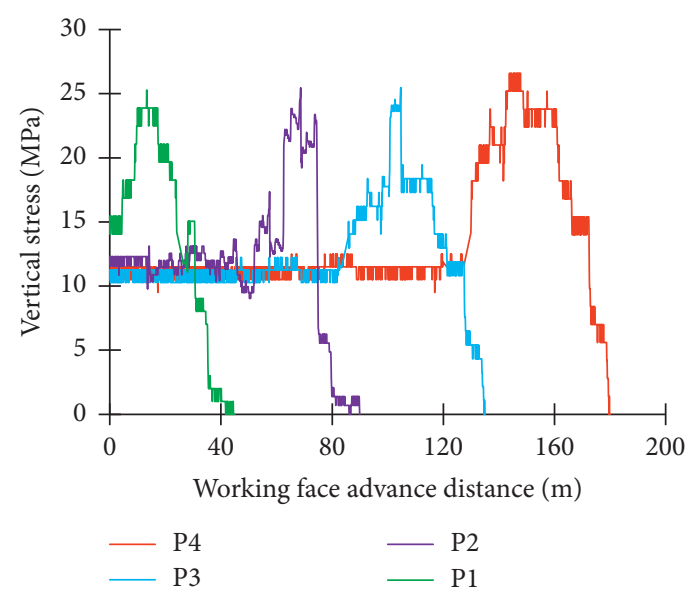

(b)

Figure 11: Characteristics of overburden movement. (a) Curves of main roof subsidence. (b) Pressure curves.

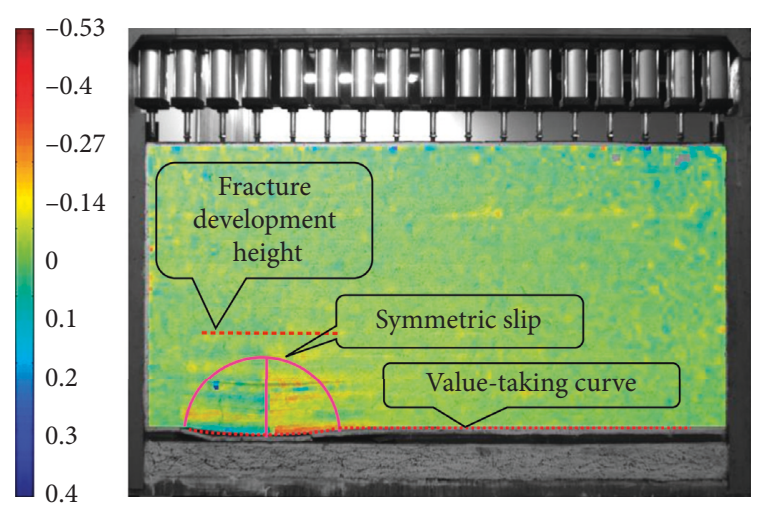

(a)
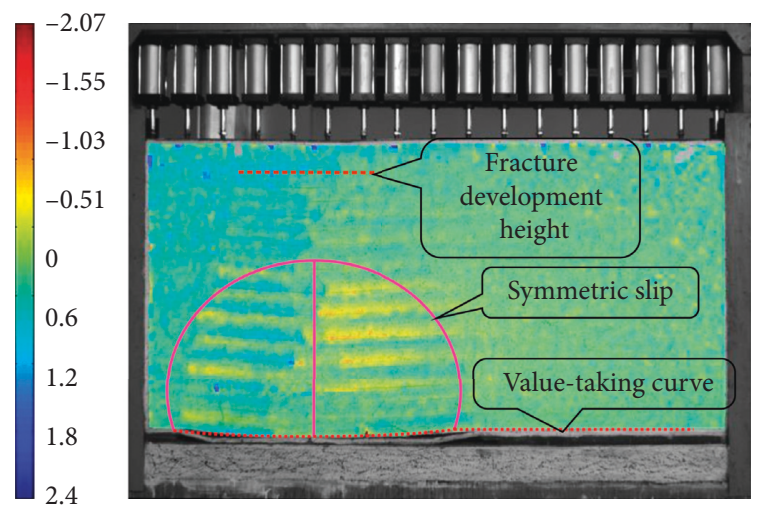

(c)
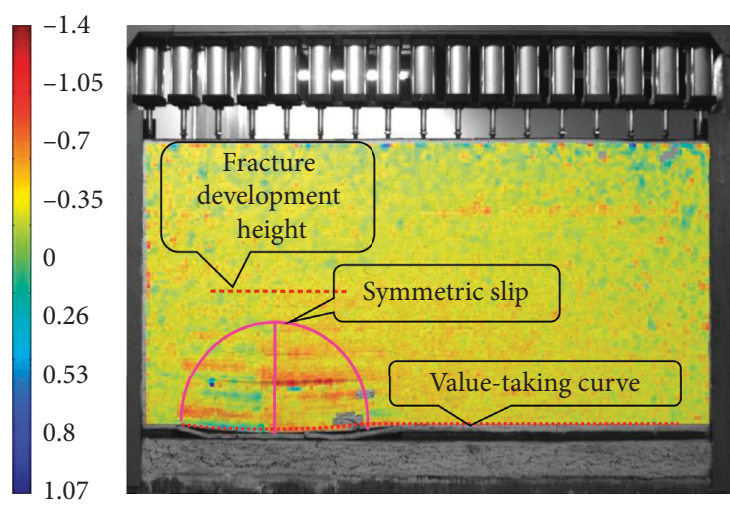

(b)
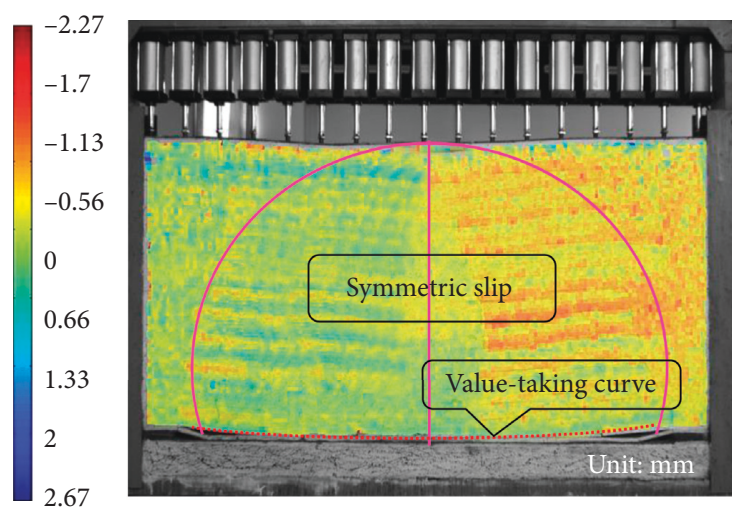

(d)

FiguRE 12: Horizontal slip contour plots in the working face with different advance distances: (a) $78 \mathrm{~m}$, (b) $117 \mathrm{~m}$, (c) $160 \mathrm{~m}$, and (d) $315 \mathrm{~m}$.

vertical directions. The horizontal length of the slip is the same as that of the overburden bedding plane fissures. The vertical length of the slip is shorter than the height of the vertical fissures. According to field measurement, the horizontal fissures are shorter than the vertical fissures.
There is no obvious bending subsidence in the strata, which means the bedding plane slip is not obvious. The overlying strata in the slight slip area in the working face have no obvious bending deformation, indicating that there is no obvious horizontal slip in this area. The 


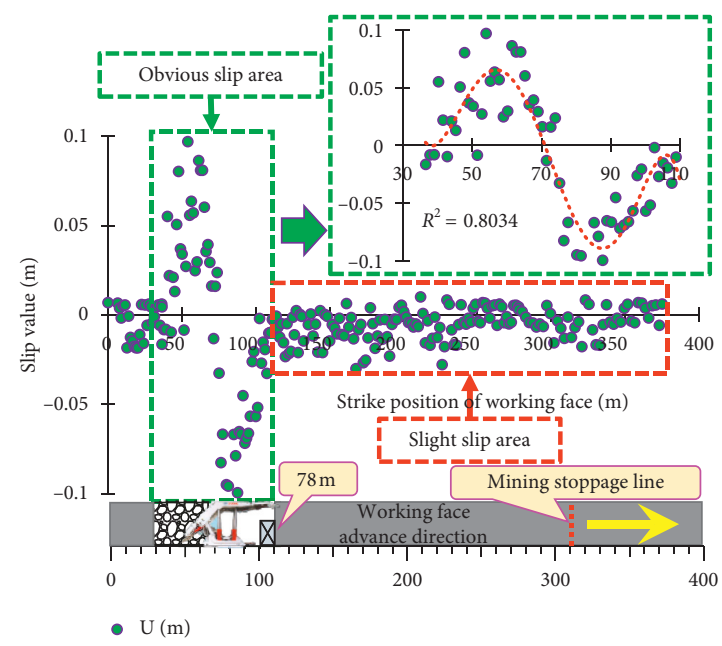

(a)

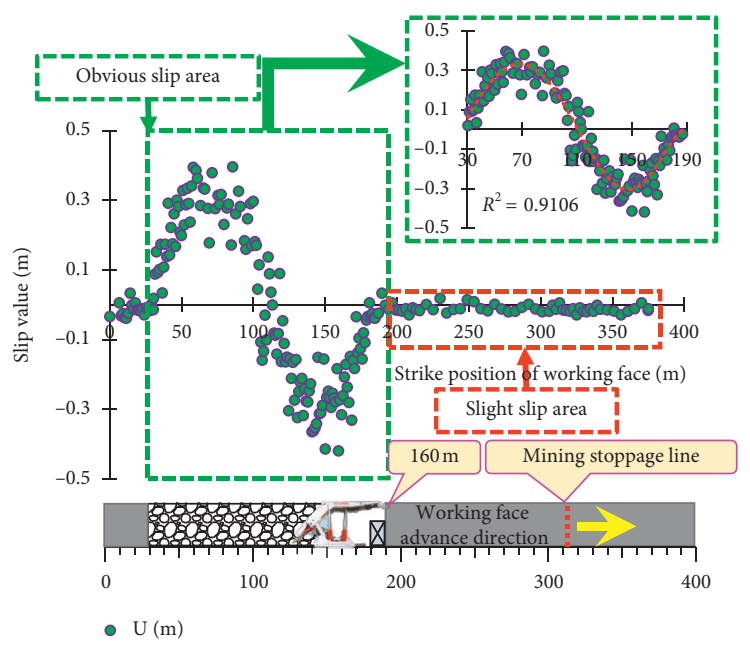

(c)

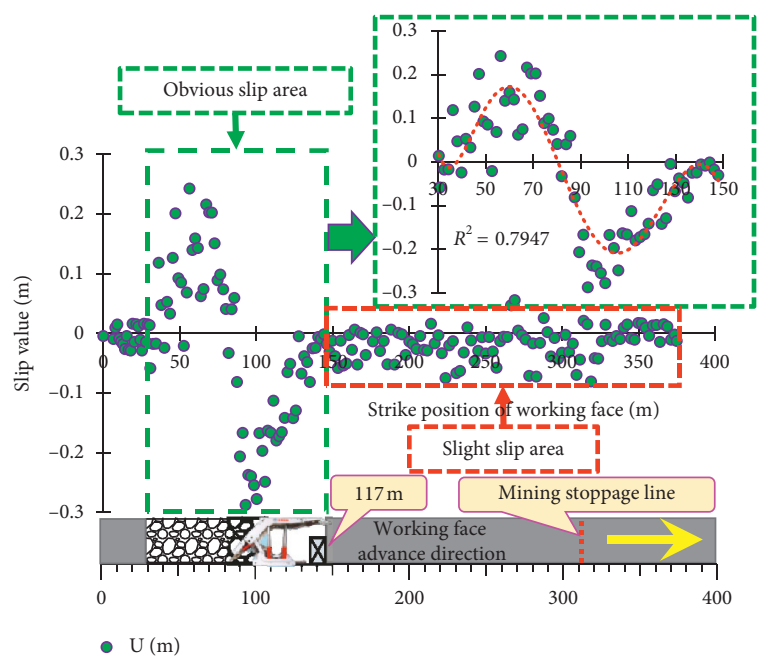

(b)

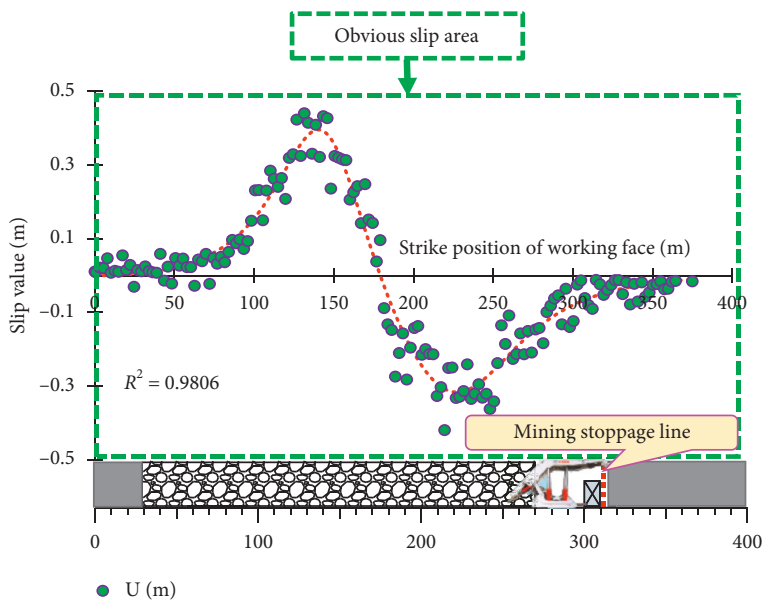

(d)

FiguRE 13: Horizontal slip curves in the working face of different advance distances. (a) $78 \mathrm{~m}$, (b) $117 \mathrm{~m}$, (c) $160 \mathrm{~m}$, and (d) $315 \mathrm{~m}$.

horizontal slip value oscillates near zero. Therefore, the range of the obvious slip area mainly depends on the size of the mining affected areas.

Figure 13 gives the horizontal slip curves of overburden when the 2211 working face is advanced to $78 \mathrm{~m}, 117 \mathrm{~m}$, $160 \mathrm{~m}$, and $315 \mathrm{~m}$, respectively. The slip curves in Figure 13 are obtained from the value-taking curve in the physical similarity simulation experiment (Figure 12). Figure 13(a) is the bedding plane slip curve between the immediate roof and the main roof when the working face advanced to $78 \mathrm{~m}$. It can be seen that the positive and negative symmetrical distribution of the bedding plane slip curves in the obvious slip zone is consistent with the results obtained from the contour plot. Meanwhile, the distribution of the slip curve of the obvious slip area is approximately an odd function relating to the center of the goaf. The maximum and minimum values of bedding plane slip are $0.06 \mathrm{~m}$ and $-0.08 \mathrm{~m}$, respectively, when the mining distance is $78 \mathrm{~m}$, appearing at the positions of $50.3 \mathrm{~m}$ and $20.4 \mathrm{~m}$ ahead of the working face, respectively. The maximum and minimum values when the working face advances to $117 \mathrm{~m}$,
$160 \mathrm{~m}$, and $315 \mathrm{~m}$ and their positions relative to the working face are given in Figure 14.

According to the contour plots, the maximum and minimum values of horizontal slip and their positions and distances away the working face can be obtained (Figure 14). It can be seen that the maximum (minimum) slip value in the obvious slip area gradually increases (decreases) and then tends to be stable, mainly because with the gradual advance of the working face, the overburden movement is fast at the beginning and then gradually becomes stable, that is, bedding plane slip in the overlying strata tends to be stable after the gradual increase. Besides, the positions of the maximum and minimum slip are moving forward, but the moving speed is lower than the advancing speed of the working face. Hence, the positions are gradually away from the work face.

\section{Discussion}

The mechanical models of the main roof with or without slip effect are established based on theoretical analysis. The 


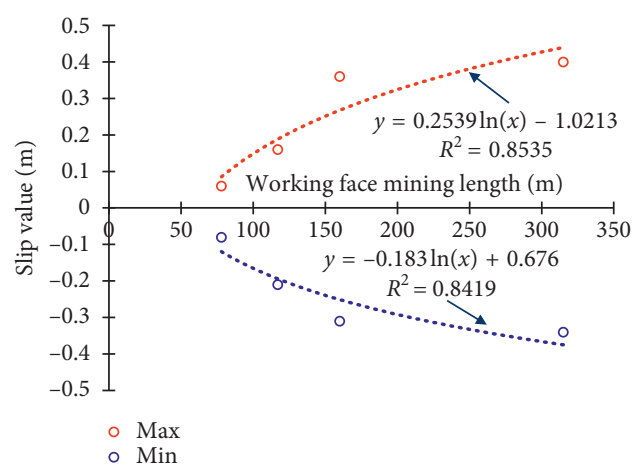

(a)

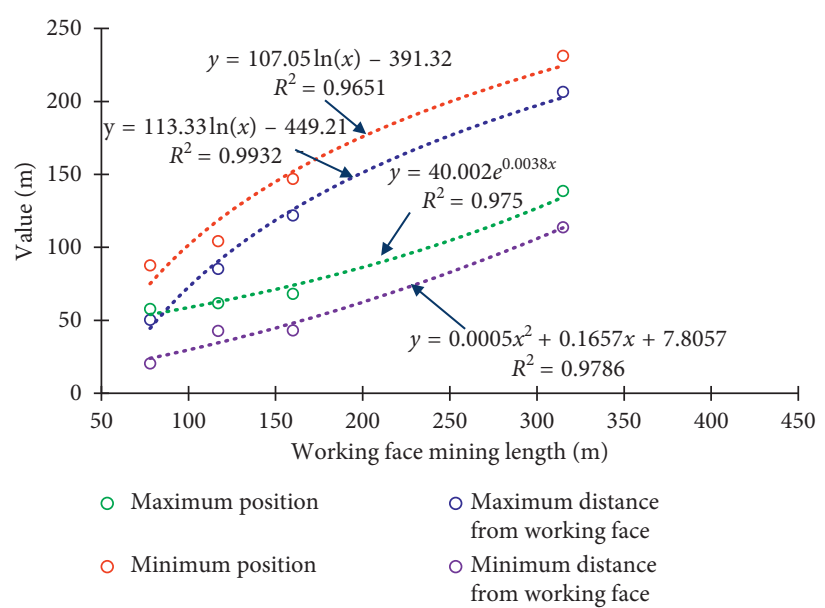

(b)

Figure 14: Evolution curves of maximum and minimum slip values and their positions. (a) Variation curves of maximum and minimum slip. (b) Evolution curves of maximum and minimum slip positions.

effect of bedding plane slip on overburden movement and failure are obtained through comparative analysis. In the process of fully mechanized top coal caving mining, with the advancement of the working face, the top coal will pass through the top coal intact zone, the top coal failure and development zone, the fissure development zone, and the top coal caving zone until the coal is completely broken and released by the coal mouth [27]. The immediate roof (claystone) and the main roof (fine sandstone) of the fully mechanized caving face in the "three-soft" coal seam are combined as a double-layer composite beam with two sides being fixed. The simplified slip mechanical model is established (Figure 15). Without considering the bedding plane slip, the mechanical model of the main roof can be directly established.

When the shear stress at the interface of the rock beam is higher than the allowable shear stress, bedding plane slip occurs in the double-layer rock beam. Bending subsidence occurs in the double-layer rock beam due to the external loading, and bending occurs in both the upper and lower strata. The differential equation of the horizontal slip between the rock layers is obtained $[28,29]$ :

$$
d u(x)=2 h_{1} w^{\prime \prime}(x)
$$

where $u(x)$ is the slip displacement, $h_{1}$ is the thickness of rock, and $w(x)$ is the deflection equation. According to the structural characteristics of overlying strata, the first-order expression of deflection of the rock beam satisfying boundary conditions is constructed by the Rayleigh method $[30,31]$ :

$$
w(x)=A e^{-\left(x^{2} / 15 l\right)} \cdot\left(x+\frac{l}{2}\right)^{2} \cdot\left(x-\frac{l}{2}\right)^{2}
$$

where $l$ is the advance distance of the working face. The function $u(x)$ of slip displacement between the strata can be obtained according to equation (1):

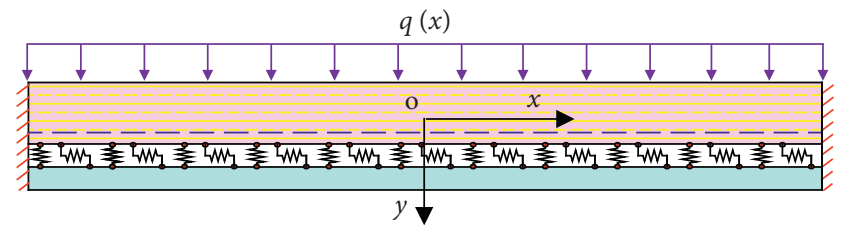

Figure 15: The mechanical model of double-layer rock beam.

$$
u(x)=-A \frac{h_{1}}{60 l} e^{-\left(x^{2} / 15 l\right)} \cdot\left(l^{2}-4 x^{2}+120 l\right) \cdot\left(l^{2}-4 x^{2}\right) .
$$

The Rayleigh-Ritz method is used to solve the deflection equation, and the deformation potential energy of the double-layer rock beam is

$$
W=\frac{1}{2} \iiint_{V_{s}} E_{s} \xi_{s}^{2} d V+\frac{1}{2} \iiint_{V_{x}} E_{x} \xi_{x}^{2} d V,
$$

where $E_{s}$ and $E_{x}$ are elastic moduli of the upper and lower strata of the double-layer rock beam, respectively, $\xi_{s}$ is the total strain of the upper stratum, and $\xi_{x}$ is the total strain of the lower stratum, which can be expressed as follows:

$$
\left\{\begin{array}{l}
\xi_{s}(y, z)=z w^{\prime \prime}(x)+\frac{E_{x} S_{x}}{E_{s} S_{s}+E_{x} S_{x}} u^{\prime}(x), \\
\xi_{x}(y, z)=z w^{\prime \prime}(x)+\frac{E_{s} S_{s}}{E_{s} S_{s}+E_{x} S_{x}} u^{\prime}(x),
\end{array}\right.
$$

where $S_{s}$ is the cross-sectional area of the upper stratum and $S_{x}$ is the cross-sectional area of the lower stratum. The potential energy $\left(V_{k}\right)$ of the double-layer rock beam induced by the external loading of the overlying strata can be derived by

$$
V_{k}=-\int_{-(l / 2)}^{(l / 2)}[q \cdot w(x)] d x .
$$


Slip potential energy produced by relative slip of upper and lower strata of double-layer rock beam is obtained by

$$
U_{h}=\frac{1}{2} \int_{-(l / 2)}^{(l / 2)} k_{s} \cdot u^{2}(x) d x,
$$

where $k_{s}$ is the equivalent average slip stiffness of the doublelayer rock beam. The total potential energy of the doublelayer rock beam $\left(\Pi_{y}=W+V_{k}+U_{h}\right)$ can be achieved, namely,

$$
\begin{aligned}
\Pi_{y}= & \frac{1}{2} \iiint_{V_{s}} E_{s} \xi_{s}^{2} d V+\frac{1}{2} \iiint_{V_{x}} E_{x} \xi_{x}^{2} d V \\
& -\int_{-(l / 2)}^{(l / 2)}[q(x) \cdot w(x)] d x+\frac{1}{2} \int_{-(l / 2)}^{-(l / 2)} k_{s} \cdot u^{2}(x) d x \\
= & \frac{1}{2} \int_{-(l / 2)}^{(l / 2)}\left\{\left[\left(E_{s} I_{s}+E_{x} I_{x}\right)+4 h_{1}^{2}\left(E_{s} I_{s 1}+E_{x} I_{x 1}\right)\right.\right. \\
& \left.\left.+4 h_{1}\left(E_{s} I_{s 2}+E_{x} I_{x 2}\right)+4 h_{1}^{2} k_{s}\right]\left[w^{\prime \prime}(x)\right]^{2} d x\right\} \\
& -\int_{-(l / 2)}^{(l / 2)}[q(x) \cdot w(x)] d x .
\end{aligned}
$$

In equation (8),

$$
\left\{\begin{array}{l}
I_{s 1}=\left(\frac{E_{x} S_{x}}{E_{s} S_{s}+E_{x} S_{x}}\right)^{2} S_{s}, \\
I_{x 1}=\left(\frac{E_{s} S_{s}}{E_{s} S_{s}+E_{x} S_{x}}\right)^{2} S_{x} \\
I_{s 2}=\left(-\frac{E_{x} S_{x} S_{s} d_{1}}{E_{s} S_{s}+E_{x} S_{x}}\right), \\
I_{x 1}=\left(-\frac{E_{s} S_{s} S_{x} d_{2}}{E_{s} S_{s}+E_{x} S_{x}}\right)
\end{array}\right.
$$

where $d_{1}$ and $d_{2}$ are the distances from the neutral axes of the upper and lower strata to the neutral axes of the cross section of the double-layer rock beam. The deformation potential energy of a thin plate is given in equation (10) if the slip effect is ignored:

$$
W=\frac{1}{2} \iiint_{V_{s}} E_{s} w_{s}^{2}(x) d V+\frac{1}{2} \iiint_{V_{x}} E_{x} w_{x}^{2}(x) d V .
$$

Potential energy $V$ generated by external loading is derived:

$$
V=-\int_{-(l / 2)}^{(l / 2)}[q \cdot w(x)] d x .
$$

Total potential energy of the rock beam is $\Pi_{n}$ and $\Pi_{n}=W+V$ :

$$
\begin{aligned}
\Pi_{n}= & \frac{1}{2} \iiint_{V_{s}} E_{s} w_{s}^{2}(x) d V+\frac{1}{2} \iiint_{V_{x}} E_{x} w_{x}^{2}(x) d V \\
& -\int_{-(l / 2)}^{l / 2}[q \cdot w(x)] d x .
\end{aligned}
$$

The total potential energy of the rock beam can be obtained as the following if the slip effect is ignored:

$$
\Pi=\left\{\begin{array}{lc}
\frac{1}{2} \iiint_{V_{s}} E_{s} \xi_{s}^{2} d V+\frac{1}{2} \iiint_{V_{x}} E_{x} \xi_{x}^{2} d V-\int_{-(l / 2)}^{l / 2}[q(x) \cdot w(x)] d x \\
\quad+\frac{1}{2} \int_{-(l / 2)}^{-(l / 2)} k_{s} \cdot u^{2}(x) d x, & \text { slip effect, } \\
\frac{1}{2} \iiint_{V_{s}} E_{s} w_{s}^{2}(x) d V+\frac{1}{2} \iiint_{V_{x}} E_{x} w_{x}^{2}(x) d V \\
\quad-\int_{-(l / 2)}^{l / 2}[q \cdot w(x)] d x, & \text { no slip effect. }
\end{array}\right.
$$

According to the principle of minimum potential energy, the variation of the total potential energy can be taken as zero [32]. The values can be obtained when the slip effect is considered or not. The stationary condition is

$$
\frac{\partial \prod}{\partial A}=0
$$

Based on the elastic theory, the relationship among deflection, bending moment, and shear force can be obtained. Then the bending moment equation of the doublelayer rock beam can be derived.

In order to verify the accuracy of the theoretical calculation, the theoretically calculated slip curve and the slip curve obtained by the similarity simulation experiment are compared. The parameters in the theoretical calculation are taken as follows: $h_{1}$ is $10.6 \mathrm{~m}, h_{2}$ is $2.1 \mathrm{~m}, E_{1}$ is $12 \mathrm{GPa}, E_{2}$ is $9.6 \mathrm{GPa}$, the overburden load $q$ is $13.25 \times 106 \mathrm{~N} / \mathrm{m}$, the equivalent average slip stiffness $k_{s}$ is $3 \mathrm{MPa}$, and the ultimate bending moment of the upper rock beam is $3.879 \times 107 \mathrm{~N} \cdot \mathrm{m}$. These parameters are substituted above equations to obtain the theoretical calculation curves.

Figure 16 compares the theoretical calculation curves and the physical simulation curves. The maximum and average values in the simulation curve in Figure 16(a) (working face advanced to $32 \mathrm{~m}$ ) are $0.096 \mathrm{~m}$ and $0.052 \mathrm{~m}$, respectively. The maximum and average values of the subsidence curve calculated with considering the slip effect are $0.097 \mathrm{~m}$ and $0.048 \mathrm{~m}$, respectively. The maximum and average values of the subsidence curve calculated without considering the slip effect are $0.078 \mathrm{~m}$ and $0.038 \mathrm{~m}$, respectively. Therefore, the calculated subsidence curve of the main roof coincides well with the physical simulation results if the slip effect is considered while the calculated subsidence of the main roof is relatively small if the slip effect is ignored. It is concluded that the slip effect enhances the subsidence of the main roof. In addition, the average value and the maximum value of the fitting curve $\left(R^{2}=0.98\right)$ obtained by the physical similarity simulation are $0.13 \mathrm{~m}$ and $0.40 \mathrm{~m}$, respectively, if the range of the working face is focused on 0 to $178.80 \mathrm{~m}$ (in the strike direction), and these values become $-0.14 \mathrm{~m}$ and $-0.34 \mathrm{~m}$ if the range is focused on 178.80 to $375 \mathrm{~m}$. In the theoretical calculation, the average and maximum slip values are $0.16 \mathrm{~m}$ and $0.37 \mathrm{~m}$, respectively, 


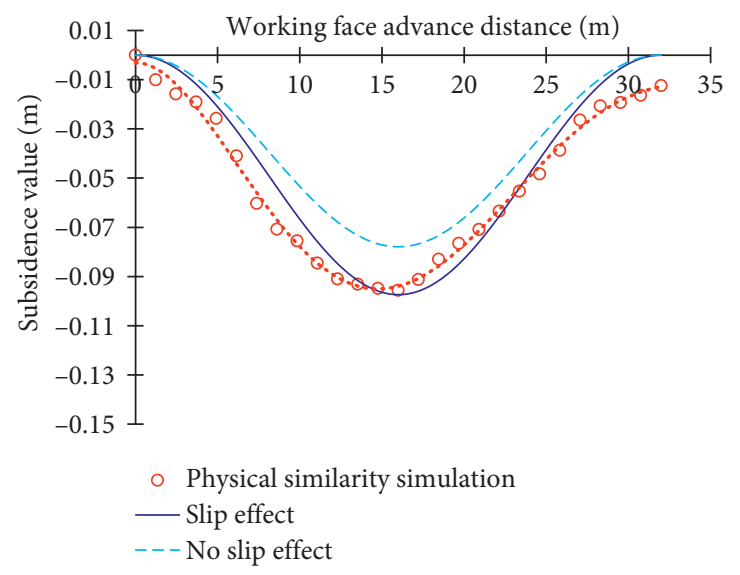

(a)

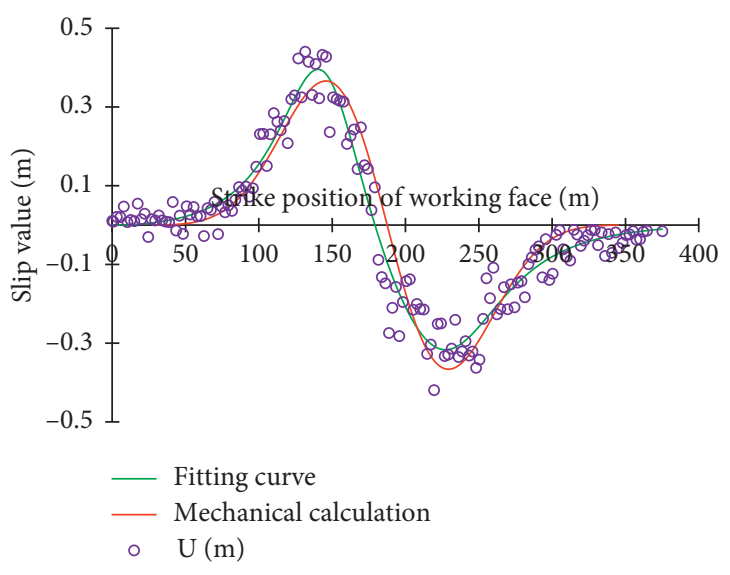

(b)

Figure 16: Comparison between theoretical calculation and physical simulation. (a) Contrast curves of subsidence amount. (b) Horizontal slip curves between theoretical calculation and similarity simulation.

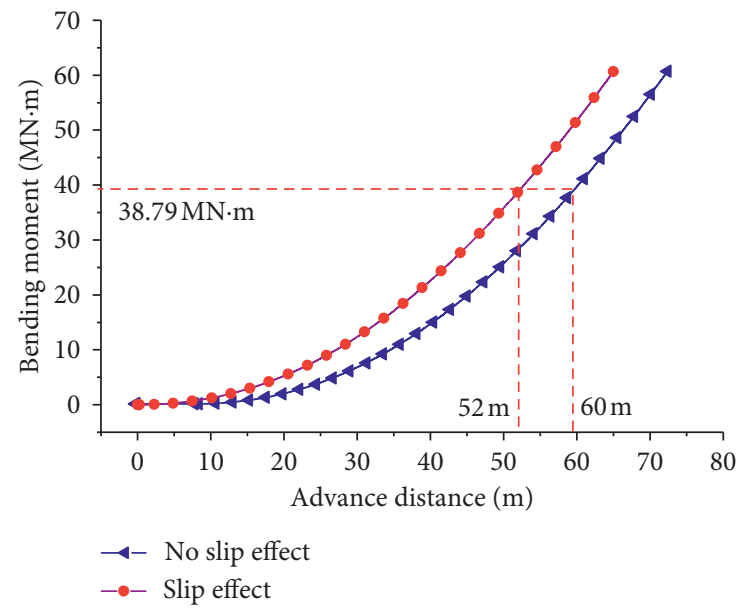

FiguRe 17: Mechanical calculation of the initial caving intervals of the main roof.

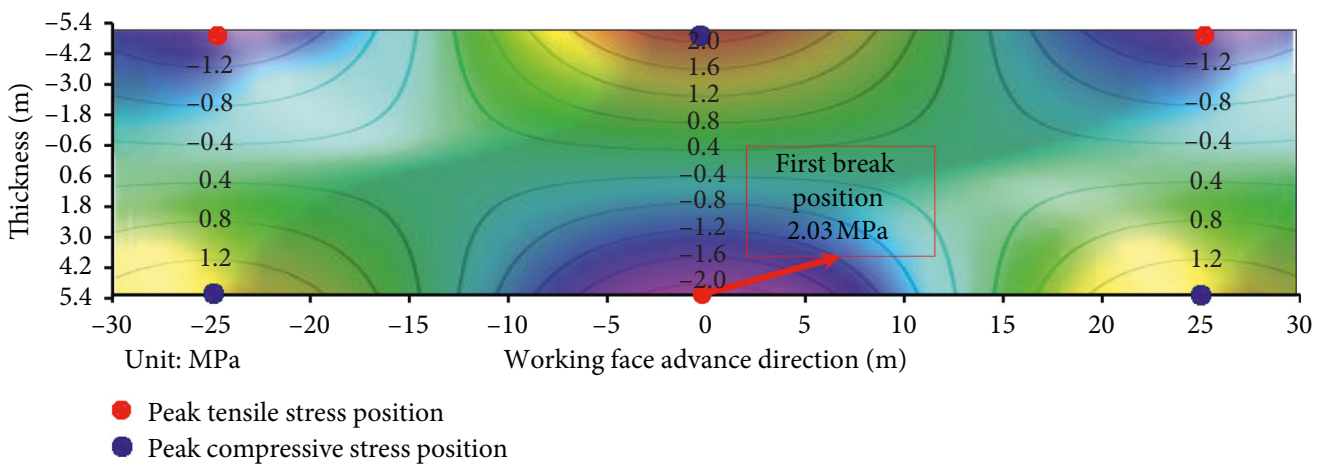

FIgURE 18: Contour plot of the orthogonal stress distribution of the main roof rock beam.

when the working face ranges from 0 to $186.80 \mathrm{~m}$, while these values are $-0.16 \mathrm{~m}$ and $-0.37 \mathrm{~m}$ when the range is focused on 186.80 to $375 \mathrm{~m}$. The fitting curves obtained by theoretical calculation are in good agreement with that derived from the physical simulation results. Hence, it is concluded that the theoretical calculation is reliable and is able to reflect the behaviors of the overlying strata and bedding plan slip.

The initial caving intervals of the main roof are theoretically calculated when the slip theory is considered or not (Figure 17). The calculated initial caving intervals are $52 \mathrm{~m}$ and $60 \mathrm{~m}$, respectively. The initial caving intervals obtained 
by field measurement and physical simulation are $51 \mathrm{~m}$ and $55 \mathrm{~m}$, respectively. The contour plot of the positive stress in the main roof beam is given in Figure 18. If the initial caving interval is assumed to be $52 \mathrm{~m}$, three peak compressive stresses and three peck tensile stresses can be found in Figure 18. Peak tensile stresses appear at the top of the front part and the back part of the rock beam, as well as the bottom of the middle part. Two peak compressive stresses appear at the bottom of the front part and the back part of the rock beam with another locating at the top of the middle part. The value of the peak tensile stress at the bottom of the main roof beam is $2.03 \mathrm{MPa}$. The result suggests that the bottom of the middle part of the rock beam tends to fracture in the early stage.

\section{Conclusion}

The results obtained lead to the following conclusions:

(1) Results of the similarity simulation experiment show that the front abutment stress distributes $50 \mathrm{~m}$ ahead of the 2211 working face at Linnancang Mine and the peak stress appears at a distance 20 to $32 \mathrm{~m}$ ahead of the working face. The initial caving interval of the main roof is $55 \mathrm{~m}$, and the periodic weighting is not obvious. The bedding plane slip in the mining direction has obvious zoning phenomenon, and the slip area is divided into the obvious slip area and the slight slip area.

(2) Based on the slip theory and the characteristics of overburden movement in the "three-soft" coal seam, a mechanical model of a double-layer rock beam is established, and the calculation equations for the deflection of the beam, horizontal slip value, and bending moment with or without slip effect are deduced. The initial caving interval under the influence of slip is calculated to be $52 \mathrm{~m}$, that is, $1 \mathrm{~m}$ different from the $51 \mathrm{~m}$ obtained by field measurement. The initial caving interval is $60 \mathrm{~m}$ without considering the slip effect, which is quite different from the result of field measurement $(51 \mathrm{~m})$. In addition, the normal stress distribution in the main roof is achieved, and the first breaking position is determined according to the calculation result.

(3) Physical similarity simulation experiment, theoretical analysis, and field measurement are adopted to study the overburden movement and bedding plane slip mechanism in the "three-soft" coal seam, and the results by these different methods are compared. The comparison demonstrates that the double-layer rock beam model proposed in this paper is reasonable and able to describe the behaviors of overlying strata and bedding plane slip, and the slip effect accelerates the overburden movement in the "three-soft" coal seam; hence, attention should be paid to the dangers caused by the slip in the "three-soft" coal seam mining.

\section{Notations}

$u(x)$ : Slip displacement

$h_{1}$ : Thickness of rock $w(x)$ : Deflection equation

$l$ : Advance distance of the working face

$E_{s}$ : $\quad$ Elastic modulus of the upper strata of the doublelayer rock beam

$E_{x}$ : Elastic modulus of the lower strata of the doublelayer rock beam

$\xi_{s}: \quad$ Total strain of the upper stratum

$\xi_{x}$ : Total strain of the lower stratum

$S_{s}$ : Cross-sectional area of the upper stratum

$S_{x}: \quad$ Cross-sectional area of the lower stratum

$V_{k}$ : Potential energy

$k_{s}$ : $\quad$ Equivalent average slip stiffness of the double-layer rock beam

$\Pi_{y}$ : $\quad$ Total potential energy of the double-layer rock beam with slip effect

$d_{1}$ : Distances from the neutral axes of the upper strata to the neutral axes of the cross section of the doublelayer rock beam

$d_{2}$ : Distances from the neutral axes of the lower strata to the neutral axes of the cross section of the doublelayer rock beam

$\Pi_{n}$ : Total potential energy of the double-layer rock beam with no slip effect.

\section{Data Availability}

The data used to support the findings of this study are available from the corresponding author upon request.

\section{Disclosure}

The authors are solely responsible for the content.

\section{Conflicts of Interest}

The authors declare no conflicts of interest.

\section{Acknowledgments}

This research was funded by the National Key R\&D Program of China (grant no. 2018YFC0604704), the National Science Fund for Distinguished Young Scholars (grant no. 51725403), and the National Natural Science Foundation of China (grant no. 51874287).

\section{References}

[1] M. C. He, H. H. Jing, and X. M. Sun, Soft Rock Engineering Mechanics, Science Press, Beijing, China, 2002.

[2] B. T. Zhao and B. Q. Lin, Gas Emission and Prevention Technology in Three Soft and Unstable Coal Seam with Low Permeability, China University of Mining and Technology, Xuzhou, China, 2007.

[3] M. Tsesarsky, E. Gal, and E. Machlav, "3-D global-local finite element analysis of shallow underground caverns in soft sedimentary rock," International Journal of Rock Mechanics and Mining Sciences, vol. 57, pp. 89-99, 2013.

[4] S. Yadav, C. Saldana, and T. G. Murthy, "Experimental investigations on deformation of soft rock during cutting," International Journal of Rock Mechanics and Mining Sciences, vol. 105, pp. 123-132, 2018. 
[5] K. F. Bizjak and B. Petkovšek, "Displacement analysis of tunnel support in soft rock around a shallow highway tunnel at Golovec," Engineering Geology, vol. 75, no. 1, pp. 89-106, 2004.

[6] R. Corthésy, M. H. Leite, D. E. Gill, and B. Gaudin, "Stress measurements in soft rocks," Engineering Geology, vol. 69, no. 3-4, pp. 381-397, 2003.

[7] J.-H. Shin, H.-G. Moon, and S.-E. Chae, "Effect of blast-induced vibration on existing tunnels in soft rocks," Tunnelling and Underground Space Technology, vol. 26, no. 1, pp. 51-61, 2011.

[8] X. Yang, E. Wang, Y. Wang, Y. Gao, and P. Wang, “A study of the large deformation mechanism and control techniques for deep soft rock roadways," Sustainability, vol. 10, no. 4, pp. 1100-1120, 2018.

[9] M. Kikumoto, V. P. Q. Nguyen, H. Yasuhara, and K. Kishida, "Constitutive model for soft rocks considering structural healing and decay," Computers and Geotechnics, vol. 91, pp. 93-103, 2017.

[10] B. Singh, R. K. Goel, J. L. Jethwa, and A. K. Dube, "Support pressure assessment in arched underground openings through poor rock masses," Engineering Geology, vol. 48, no. 1-2, pp. 59-81, 1997.

[11] D. Qin, X. Wang, D. Zhang, and X. Chen, "Study on surrounding rock-bearing structure and associated control mechanism of deep soft rock roadway under dynamic pressure," Sustainability, vol. 11, no. 7, pp. 1892-1907, 2019.

[12] M. He, W. Gong, J. Wang et al., "Development of a novel energy-absorbing bolt with extraordinarily large elongation and constant resistance," International Journal of Rock Mechanics and Mining Sciences, vol. 67, pp. 29-42, 2014.

[13] G. F. Wang and Y. H. Pang, "Full-mechanized coal mining and caving mining method evaluation and key technology for thick coal seam," Journal of China Coal Society, vol. 43, no. 1, pp. 33-42, 2018.

[14] A. Vakili and B. K. Hebblewhite, "A new cavability assessment criterion for longwall top coal caving," International Journal of Rock Mechanics and Mining Sciences, vol. 47, no. 8, pp. 1317-1329, 2010.

[15] B. Unver and N. E. Yasitli, "Modelling of strata movement with a special reference to caving mechanism in thick seam coal mining," International Journal of Coal Geology, vol. 66, no. 4, pp. 227-252, 2006.

[16] F. Gao, D. Stead, and J. Coggan, "Evaluation of coal longwall caving characteristics using an innovative UDEC trigon approach," Computers and Geotechnics, vol. 55, pp. 448-460, 2014.

[17] Y. P. Wu, D. Lang, and P. S. Xie, "Mechanism of disaster due to rib spalling at fully-mechanized top coal caving face in soft steeply dipping seam," Journal of China Coal Society, vol. 41, no. 8, pp. 1878-1884, 2016.

[18] X. F. Wang, Y. Wang, and D. S. Zhang, "Enhanced support technology for key area of the roadway in large inclined angle "three-soft" coal seam," Journal of Mining and Safety Engineering, vol. 34, no. 2, pp. 208-213, 2017.

[19] M. G. Xu, P. Wei, S. G. Li, and J.-J. Wang, "Experimental study on overburden migration and fracture evolution law of "three soft" coal seam fully mechanized working-face," Journal of China Coal Society, vol. 42, no. 1, pp. 122-127, 2017.

[20] Q. L. Yao, S. G. Cao, F. H. Wang, and Z.-G. Jiang, "Applicability of combined slip support of large mining height in three-soft coal seam of medium-thickness," Journal of Mining and Safety Engineering, vol. 27, no. 2, pp. 185-189, 2010.
[21] J. C. Wang, "Engineering practice and theoretical progress of top-coal caving mining technology in China," Journal of China Coal Society, vol. 43, no. 1, pp. 43-51, 2018.

[22] M. He, "Latest progress of soft rock mechanics and engineering in China," Journal of Rock Mechanics and Geotechnical Engineering, vol. 6, no. 3, pp. 165-179, 2014.

[23] H. Liu, J. Zhang, W. Zhang, F. Gao, H. Yan, and T. L. An, "Experimental investigation of perceptual characteristics of functional cemented backfilling materials in coal mines," Minerals, vol. 9, no. 1, pp. 55-70, 2019.

[24] Q. Sun, J. Zhang, Q. Zhang, and X. Zhao, "Analysis and prevention of geo-environmental hazards with high-intensive coal mining: a case study in China's western eco-environment frangible area," Energies, vol. 10, no. 6, pp. 786-801, 2017.

[25] Y. Huang, J. Zhang, W. Yin, and Q. Sun, "Analysis of overlying strata movement and behaviors in caving and solid backfilling mixed coal mining," Energies, vol. 10, no. 7, pp. 1057-1073, 2017.

[26] Q. Sun, J. Zhang, and N. Zhou, "Study and discussion of shortstrip coal pillar recovery with cemented paste backfill," International Journal of Rock Mechanics and Mining Sciences, vol. 104, pp. 147-155, 2018.

[27] J. H. Wang, Z. Z. Huang, and L. Yu, "Three plies in top coal" theory and its application in top coal caving mining for ultrathick coal seams," Journal of China Coal Society, vol. 42, no. 4, pp. 809-816, 2017.

[28] H. T. Sun, Study on the deformation fracture mechanism of the surface borehole with the excavation disturbance, Ph.D. thesis, Chongqing University, Chongqing, China, 2008.

[29] D. Y. Liu, H. T. Sun, and Y. Zhang, "A model of shear slipping of overlying strata under mining disturbance," Rock and Soil Mechanics, vol. 31, no. 2, pp. 609-614, 2010.

[30] Y. Pan, S. T. Gu, and Y. S. Qi, "Analytic solution of tight roof's bending moment deflection and shear force under advanced supercharger load and supporting resistance before first weighting," Chinese Journal of Rock Mechanics and Engineering, vol. 32, no. 8, pp. 1544-1553, 2013.

[31] Z. L. Xu, Concise Tutorial on Elastic Mechanics, Advanced Education, Beijing, China, 2013.

[32] H. A. F. A. Santos and C. I. Almeida Paulo, "On a pure complementary energy principle and a force-based finite element formulation for non-linear elastic cables," International Journal of Non-Linear Mechanics, vol. 46, no. 2, pp. 395-406, 2011. 


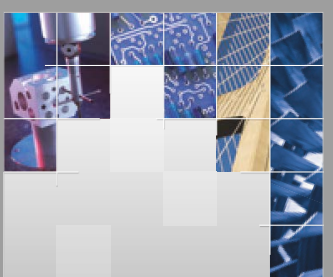

\section{Enfincering}
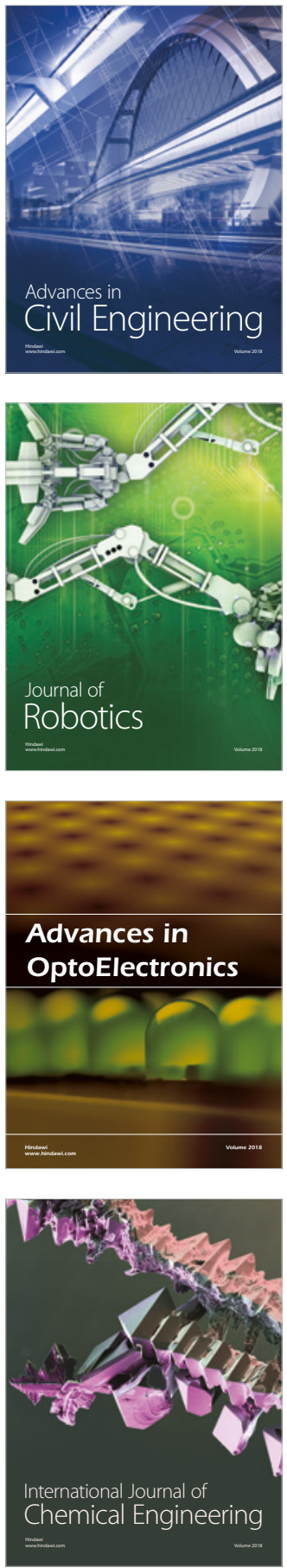

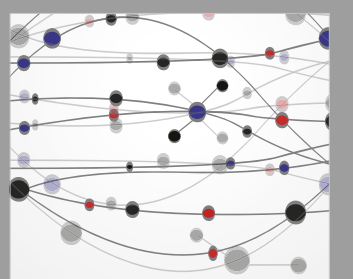

\section{Rotating \\ Machinery}

The Scientific World Journal

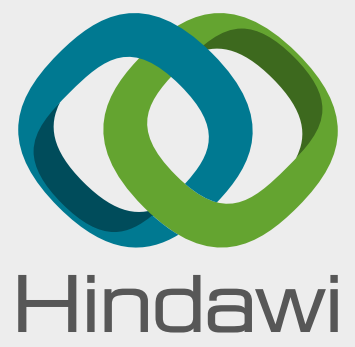

Submit your manuscripts at

www.hindawi.com
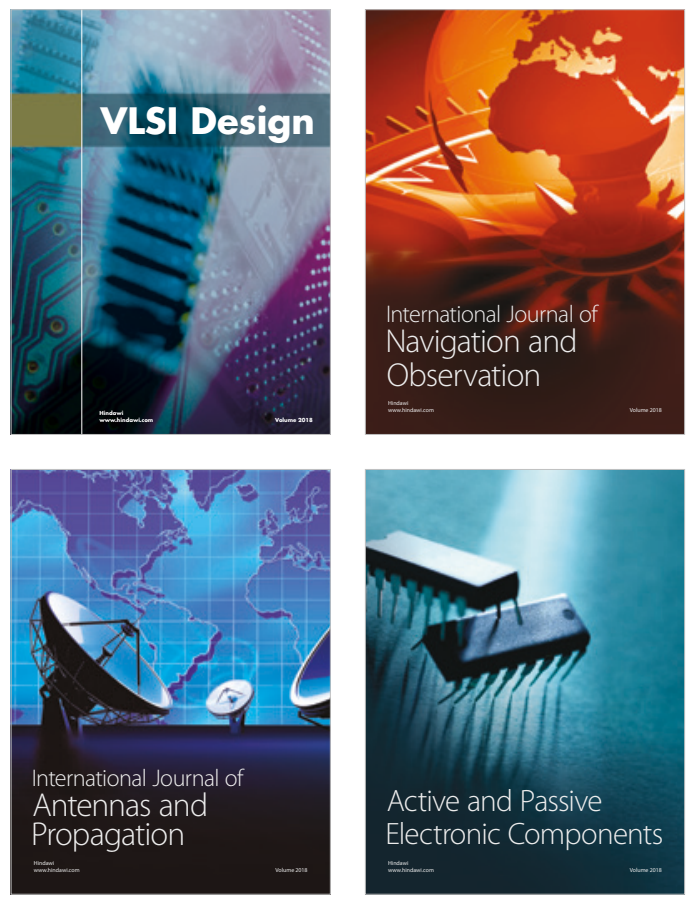
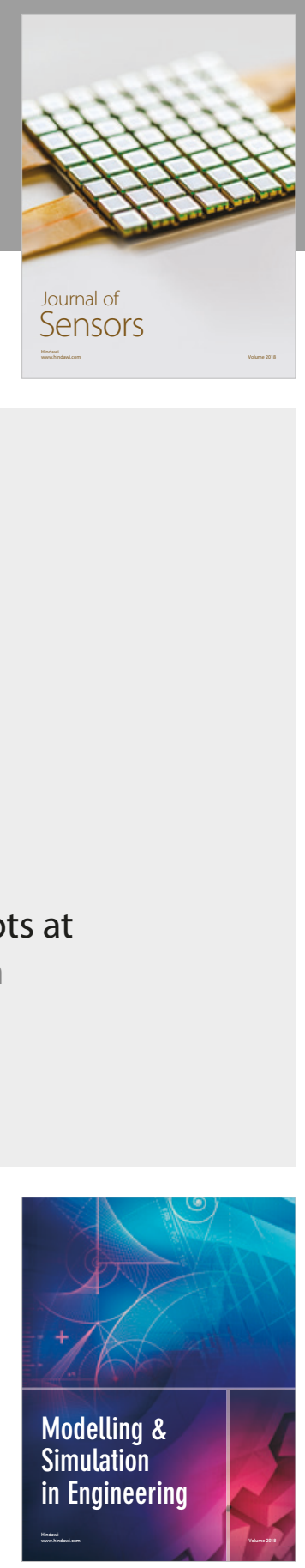

\section{Advances \\ Multimedia}
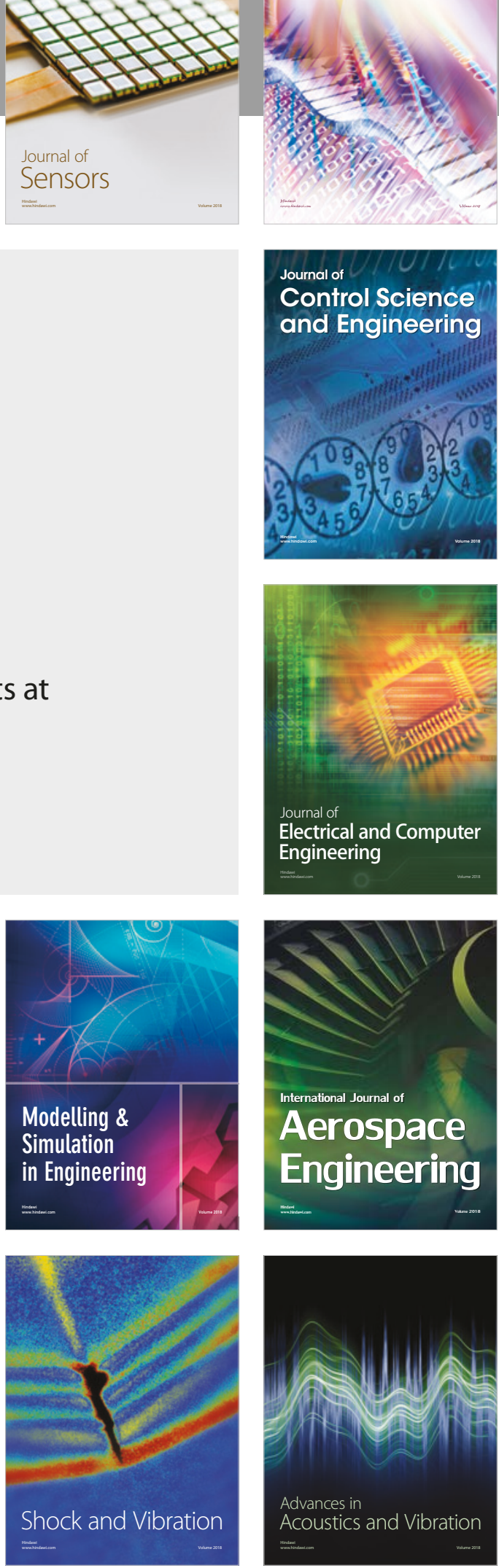